Document downloaded from:

http://hdl.handle.net/10251/140969

This paper must be cited as:

Plazas, M.; Nguyen, HT.; González-Orenga, S.; Fita, A.; Vicente, O.; Prohens Tomás, J.; Boscaiu, M. (10-2). Comparative analysis of the responses to water stress in eggplant (Solanum melongena) cultivars. Plant Physiology and Biochemistry. 143:72-82. https://doi.org/10.1016/j.plaphy.2019.08.031

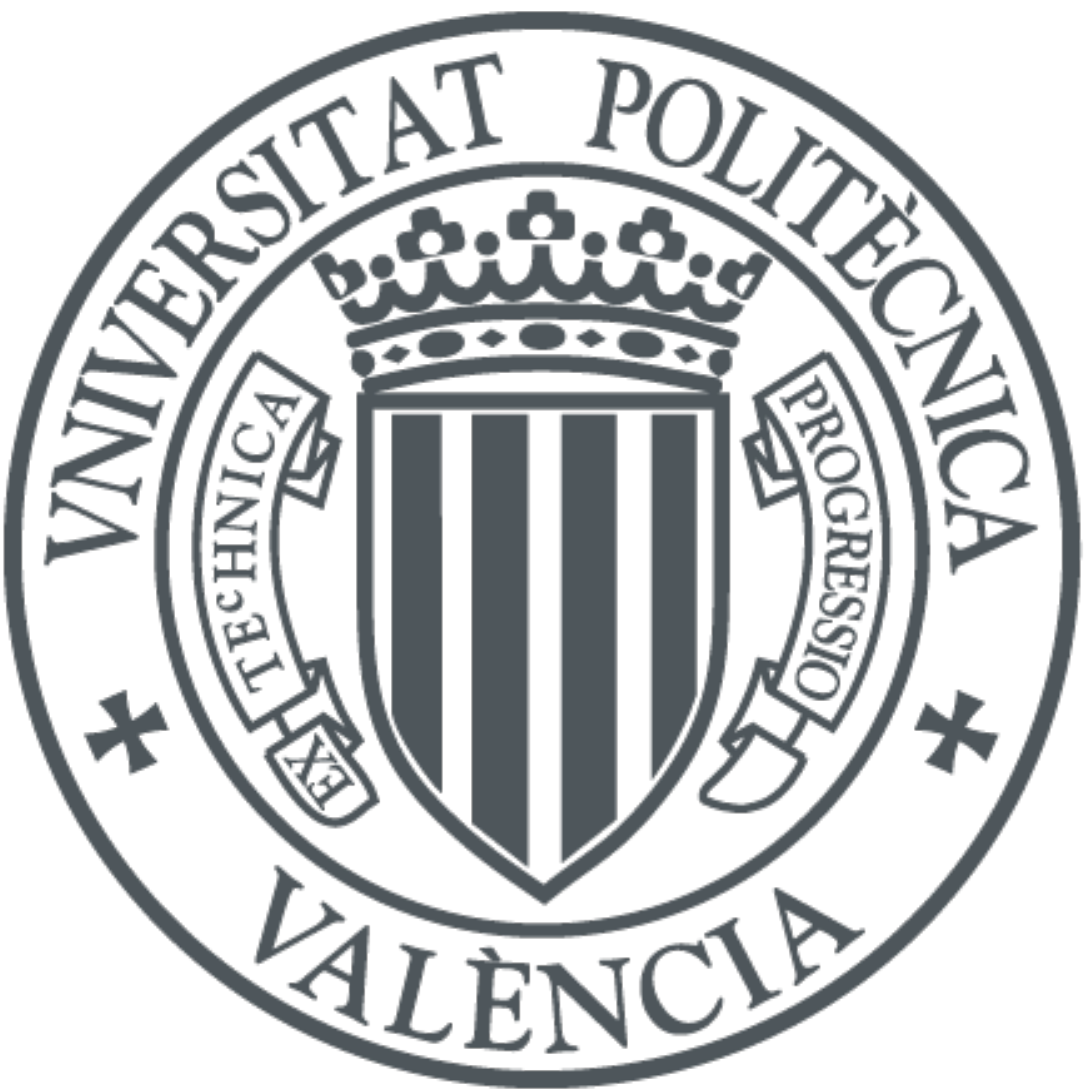

The final publication is available at

https://doi.org/10.1016/j.plaphy.2019.08.031

Copyright Elsevier

Additional Information 


\title{
Comparative analysis of the responses to water stress in eggplant (Solanum melongena) cultivars
}

\author{
Mariola Plazas ${ }^{1}$, Huu Trong Nguyen ${ }^{2}$, Sara González-Orenga ${ }^{3}$, Ana Fita ${ }^{1}$, Oscar \\ Vicente $^{4}$, Jaime Prohens ${ }^{1, *}$, Monica Boscaiu ${ }^{3}$
}
${ }^{1}$ Instituto de Conservación y Mejora de la Agrodiversidad Valenciana, Universitat Politècnica de València, Camino de Vera 14, 46022 Valencia, Spain
${ }^{2}$ Laboratory of Induced Resistance and Plant Bioprotection RIBP, University of Reims Champagne-Ardenne, 51678 Reims Cedex 2, France
${ }^{3}$ Instituto Agroforestal Mediterráneo, Universitat Politècnica de València, Camino de Vera 14, 46022 Valencia, Spain
${ }^{3}$ Instituto de Biología Molecular y Celular de Plantas (IBMCP, UPV-CSIC), Universitat Politècnica de València, Camino de Vera 14, 46022 Valencia, Spain

*Corresponding author.

E-mail address: jprohens@btc.upv.es (J. Prohens)

\section{ABSTRACT}

Little information is available on the physiological and biochemical responses to water stress in eggplant (Solanum melongena). We evaluated four genetically diverse eggplant varieties (MEL3-MEL6) under control and water stress conditions.

Measurements were taken for plant growth, tissue water content traits, content in chlorophylls a and b, carotenoids, proline, malondialdehyde, total phenolics, total flavonoids, superoxide dismutase, catalase (CAT), ascorbate peroxidase (APX), and glutathione reductase (GR) activities. For most traits, the water stress treatment had a greater contribution than the variety effect to the total sums of squares in an ANOVA analysis, except for total flavonoids, SOD, APX, and GR. The water stress treatment had a strong effect on plant growth and tissue water content. In general, water stress reduced the three photosynthetic pigments, increased proline, malondialdehyde, total phenolics, and total flavonoids, although some varietal differences were observed. Different patterns were also detected in the activities of the four enzymes evaluated, but few differences were observed for individual varieties between the control and water 
stress treatments. Many significant phenotypic correlations were observed among the traits studied, but only eight environmental correlations were detected. A PCA analysis distinctly separated individuals according to the treatment, and revealed a clearer separation of varieties under water stress than under control conditions, pointing to varietal differences in the responses to stress. Our results suggest that proline could be used as a marker for drought stress tolerance in this species, and provide relevant information about the physiological and biochemical responses of eggplant to drought stress.

Keywords:

Drought

Solanum melongena

Photosynthetic pigments

Proline

malondialdehyde

Antioxidants

Enzymatic activities

\section{Introduction}

Eggplant (Solanum melongena L.) is an important vegetable crop in many tropical and subtropical areas of the world. According to FAO statistics, eggplant ranks $6^{\text {th }}$, after tomatoes, watermelons, onions, cucumbers, and cabbages, in total global production, with 52.3 million tons produced in 2017 (FAO, 2019). In addition, eggplant is one of the 35 food crops considered as most important for global food security and, as such, is included in the Annex 1 of the International Treaty on Plant Genetic Resources for Food and Agriculture (Fowler et al., 2003). Many of the areas where eggplant is cultivated are already suffering dramatic modifications in the current agricultural environment, which will aggravate in the future, due to the ongoing climate change (Anwar et al., 2013).

Reductions in the eggplant productivity results from a number of factors that will be intensified in the near future, including increased abiotic stresses derived from 
climate change (Kirnak et al., 2002; Lovelli et al., 2007; Karam et al., 2011; Tani et al., 2018). Global warming represents one of the major threats for agriculture, and increased temperatures, alteration of normal seasonal weather patterns, 'heat waves', and more frequent, longer, and more intense drought spells, will be especially intense in arid and semiarid regions, where there is already a scarcity of water for irrigation (IPCC, 2014). Therefore, in these areas, drought may be considered as one of the most limiting factors for crop production, in particular for vegetables such as eggplant that require large amounts of water (Lovelli et al., 2007; Karam et al., 2011).

Research on the responses of crops to abiotic stresses and on the mechanisms underlying these responses is growing and contributing to the design of strategies for the genetic improvement of crop stress tolerance (Fita et al., 2015; Van Oosten et al., 2016; Nakashima and Suenaga, 2017). General responses of plants to abiotic stresses include a reduction of growth, an alteration of the shoot/root ratio, degradation of photosynthetic pigments, and activation of mechanisms of defence, such as the synthesis and accumulation of different osmolytes for cellular osmotic adjustment or the activation of antioxidant systems (Kaur and Asthir, 2015; Anjum et al., 2017; Arbona et al., 2017; Singh et al., 2017). Drought stress is associated with increased production and accumulation of reactive oxygen species (ROS), leading to oxidative stress and the activation of antioxidant mechanisms (Das and Roychoudhury, 2014; Choudhury et al., 2017). Phenols, flavonoids, ascorbic acid, and carotenoids are amongst the most common antioxidant metabolites (Panche et al., 2016; Sun et al., 2018; Vicente and Boscaiu, 2018), whereas superoxide dismutase (SOD), catalase (CAT), ascorbate peroxidase (APX) (and other peroxidases), or redox regulatory enzymes such as glutathione reductase (GR) represent the most relevant antioxidant enzymatic systems activated in plants to counteract the deleterious effects of oxidative stress (Gill and Tuteja, 2010, Karuppanapandian et al., 2011).

Not much information is available on the mechanisms of response and tolerance to drought in eggplant. In this way, drought has been found to reduce leaf chlorophyll contents (Kirnak et al., 2002; Gobu et al., 2017), and to increase proline (Sarker et al., 2004, 2005; Tani et al., 2018), hydrogen peroxide and malondialdehyde (Tani et al., 2018) concentrations in eggplant. Also, a two-year study by Helyes et al. (2015) did not reveal significant differences in the total phenolics content in the fruit of eggplant as a consequence of water deficit stress. All the aforementioned studies were performed using a single eggplant variety, except that of Tani et al. (2018), which involved two 
varieties. In the close eggplant relative S. aethiopicum (Prohens et al., 2012), studies with several accessions found an increase in proline, glutamate, sucrose, fructose and tricarboxylic acid cycle metabolites concentrations, and a decrease in the chlorophylls and total carotenoids contents in response to drought stress (Mibei et al., 2017a, 2017b).

Given the lack of systematic studies to evaluate the physiological and biochemical mechanisms of response and tolerance to drought in diverse eggplant materials, we compared the responses to water stress in four varieties of eggplant with the aim of generating novel information on the mechanisms that are activated under drought conditions in this important vegetable crop. Therefore, we correlated the reduction of vegetative growth and tissue water content with: (i) photosynthetic pigments degradation; (ii) accumulation of proline, as one of the commonest osmolyte in plants; (iii) levels of malondialdehyde, as a reliable oxidative stress marker; (iv) accumulation total phenolic and flavonoid contents, as non-enzymatic antioxidants; and, (v) specific activities of four antioxidant enzymes: superoxide dismutase (SOD), catalase (CAT), glutathione reductase (GR), and ascorbate peroxidase (APX).

\section{Material and methods}

\subsection{Plant material and experimental design}

Four S. melongena varieties corresponding to stable open-pollinated local varieties (MEL3, MEL4, MEL5 and MEL6) were used for the present study. These varieties are placed in different branches of an eggplant genetic relationships phenogram, although the Dice's genetic similarity coefficient is in all cases above 0.9 (Acquadro et al., 2017). The four varieties are morphologically very different in plant and fruit traits (Kaushik et al., 2016). In this way, MEL3 has medium sized semi-long green fruits, MEL4 has medium-sized round black fruits, MEL5 has medium sized semi-long light purple fruits, and MEL6 has large long purple fruits (Kaushik et al., 2016). Seeds of the four varieties are conserved in the germplasm bank of Universitat Politècnica de València (FAO code ESP026) and are available from both the corresponding author (JP) and the germplasm bank. Seeds of each of them were germinated in Petri dishes using the protocol described by Ranil et al. (2015).

Germinated seeds were transferred to seedling trays containing Humin-substrat N3 (Klasmann-Deilmann, Germany) substrate and kept in a climatic chamber with a $14 \mathrm{~h}$ light / $10 \mathrm{~h}$ dark photoperiod and a $25^{\circ} \mathrm{C}$ (light) / $18^{\circ} \mathrm{C}$ (dark) temperature regime. When 
the stem of the plantlets reached a length of 6-8 cm, they were transferred to individual 1.3 L Serie CD alto (14.5 cm of external diameter and $12.5 \mathrm{~cm}$ of height) thermoformed pots (Projar, Quart de Poblet, Spain) filled with the same Humin-substrat N3 substrate and kept in a greenhouse with controlled temperature (maximum of $30^{\circ} \mathrm{C}$ and minimum of $15^{\circ} \mathrm{C}$ ). Plants were irrigated with tap water so that the substrate was always sufficiently moistened to avoid any water deficit stress. When all plants developed at least five true leaves, ten plants with similar size from each variety were selected to be used for the experiment, and randomly assigned to two groups (control and water stress treatment) of five plants each. Control and treated plants were distributed at random in a greenhouse bench. Control plants were watered every two days with tap water (300 $\mathrm{mL} / \mathrm{pot}$ ) allowing free drainage of excess water. The water stress treatment was performed by completely withholding irrigation of the plants. Pots of both control and water stress treatments were elevated from the bench surface by placing an inverted Petri dish (9 $\mathrm{cm}$ in diameter) below each pot, to allow drainage in control plants and to avoid absorption of drainage water through the base of the pot in the stressed plants. Substrate humidity (\% vol) was measured every other day throughout the treatments with a WET-2 Sensor (Delta - T Devices, Cambridge, UK). Eleven days after starting the treatments the experiment was finished and the aerial part of all plants were cut and separated into stem and leaves. At this stage plants had not yet started flowering. The substrate was washed out from the roots, which were also collected. All traits were measured in each of the five individual plants of each combination of variety $x$ treatment in the experiment. For the plant growth and tissue water content traits, measures were taken for roots, stem, and leaves, while for photosynthetic pigments, proline, malondialdehyde, non-enzymatic antioxidants, and antioxidant enzyme activity, measurements were performed in leaves.

\subsection{Plant growth and tissue water content}

The initial length of stem was measured at the beginning of the treatments. The following growth parameters were determined at the end of the experiment: length of the stem, fresh weight of roots, fresh weight of stem, and the fresh weight of leaves. To obtain the water content, part of the fresh material was weighed (fresh weight; FW), dried for four days at $65^{\circ} \mathrm{C}$, until constant weight, and then weighed again (dry weight; DW); the water content (WC) percentage was calculated by the following formula: WC $(\%)=((F W-D W) / F W) \times 100$ (Gil et al., 2014). 


\subsection{Photosynthetic pigments}

Total carotenoids, chlorophyll a and chlorophyll b were measured following Lichtenthaler and Wellburn (1983). Ten mL of ice-cold 80\% (v/v) acetone was used to extract the pigments from $0.05 \mathrm{~g}$ of fresh leaf material. After mixing overnight and centrifuging for $10 \mathrm{~min}$ at $12000 \mathrm{rpm}$, the supernatant was collected, and its absorbance was measured at 663, 646, and $470 \mathrm{~nm}$. Chlorophyll a, chlorophyll b, and carotenoids concentrations were calculated using the equations described by Lichtenthaler and Wellburn (1983). Pigment concentrations were expressed in $\mathrm{mg} \mathrm{g}^{-1} \mathrm{DW}$.

\subsection{Proline quantification}

Proline concentration was determined in fresh plant material by the ninhydrinacetic acid method described by Bates et al. (1973). Proline was extracted in 3\% aqueous sulfosalicylic acid, the extract was mixed with acid ninhydrin solution, incubated for $1 \mathrm{~h}$ at $95^{\circ} \mathrm{C}$, cooled on ice and then extracted with two volumes of toluene. The absorbance of the supernatant was read at $520 \mathrm{~nm}$, using toluene as a blank. Proline concentration was expressed as $\mu \mathrm{mol} \mathrm{g}{ }^{-1} \mathrm{DW}$.

\subsection{Malondialdehyde and non-enzymatic antioxidants}

Extracts were prepared from fresh leaf material in $80 \%$ methanol, in a rocker shaker, for 24-48 h. Malondialdehyde concentration was determined following the method described by Hodges et al. (1999). The samples were mixed with $0.5 \%$ thiobarbituric acid (TBA) prepared in 20\% TCA (or with 20\% TCA without TBA for the controls), and then incubated at $95^{\circ} \mathrm{C}$ for $20 \mathrm{~min}$. After stopping the reaction on ice, the absorbance of the supernatants was measured at $532 \mathrm{~nm}$. The non-specific absorbance at 600 and $440 \mathrm{~nm}$ was subtracted and malondialdehyde concentration determined using the equations by Hodges et al. (1999).

Total phenolic compunds were quantified by reaction with the Folin-Ciocalteu reagent following the method described by Blainski et al. (2013). The methanol extracts were mixed with sodium bicarbonate and the reagent, and absorbance was recorded at $765 \mathrm{~nm}$ using gallic acid (GA) as standard. The measured total phenolics concentrations were expressed as GA equivalents (mg eq. $\mathrm{GA} \mathrm{g}^{-1} \mathrm{DW}$ ).

Total 'antioxidant flavonoids' were determined by the reaction with $\mathrm{NaNO}_{2}$ and $\mathrm{AlCl}_{3}$ at a basic $\mathrm{pH}$, as described by Zhishen et al. (1999), with catechin (C) used as 
standard. The absorbance of the samples was measured spectrophotometrically, at 510 nm. Although this method is considered for detection of 'total flavonoids' in the sample, this is not strictly true. The method is based on the nitration of aromatic rings containing a catechol group. Several groups of flavonoids (e.g., flavonols and flavanols) but also other phenolics, such as caffeic acid and derivatives, react in this way. Nevertheless, phenolic compounds detected in the assay are all strong antioxidants and there is a good correlation between their levels and the total antioxidant activity of the samples (Zhishen et al. 1999). To simplify, $\mathrm{AlCl}_{3}$-reactive compounds will be referred throughout the text simply as “total flavonoids”, and their concentrations expressed as equivalents of catechin (mg eq. $\mathrm{C} \mathrm{g}^{-1} \mathrm{DW}$ ).

\subsection{Antioxidant enzyme activity assays}

Crude protein extracts were prepared from fresh plant material as described by Gil et al. (2014). Samples were ground in liquid $N_{2}$ and then mixed with extraction buffer [20 mM Hepes, pH 7.5, 50 mM KCl, 1 mM EDTA, 0.1\% (v/v) Triton X-100, $0.2 \%(\mathrm{w} / \mathrm{v})$ polyvinylpyrrolidone, $0.2 \%(\mathrm{w} / \mathrm{v})$ polyvinylpolypyrrolidone, and $5 \%(\mathrm{v} / \mathrm{v})$ glycerol]. A 1/10 volume of 'high salt buffer' (225 mM Hepes, pH 7.5, $1.5 \mathrm{M} \mathrm{KCl}$, and $22.5 \mathrm{mM} \mathrm{MgCl}_{2}$ ) was added to each sample, and the homogenates were centrifuged for $20 \mathrm{~min}$ at 20,000 $\mathrm{x} \mathrm{g}$ and $4^{\circ} \mathrm{C}$. Supernatants were collected, concentrated in U-TubeTM concentrators (Novagen, Madison, USA), and centrifuged to remove precipitated material. The final samples (referred to as 'protein extracts') were divided into aliquots, flash-frozen in liquid $\mathrm{N}_{2}$ and stored at $-75^{\circ} \mathrm{C}$ until used for enzyme assays. Protein concentration in the extracts was determined by the method of Bradford (1976), using bovine serum albumin as a standard and the Bio-Rad commercial reagent.

Superoxide dismutase (SOD) activity in the protein extracts was determined according to Beyer and Fridovich (1987), by following spectrophotometrically (at 560 $\mathrm{nm}$ ) the inhibition of nitrobluetetrazolium (NBT) photoreduction, in reaction mixtures containing riboflavin as the source of superoxide radicals. One SOD unit was defined as the amount of enzyme causing 50\% inhibition of NBT photoreduction under the assay conditions. Catalase (CAT) activity was analysed as indicated by Aebi (1984), following the decrease in absorbance at $240 \mathrm{~nm}$ which accompanies the consumption of $\mathrm{H}_{2} \mathrm{O}_{2}$ added to protein extracts. One CAT unit was defined as the amount of enzyme that will decompose $1 \mathrm{mmol}$ of $\mathrm{H}_{2} \mathrm{O}_{2}$ per minute at $25^{\circ} \mathrm{C}$. Ascorbate peroxidase (APX) activity was determined according to Nakano and Asada (1981), by measuring the 
decrease in absorbance at $290 \mathrm{~nm}$ as ascorbate becomes oxidized in the reaction. One APX unit was defined as the amount of enzyme required to consume $1 \mathrm{mmol}$ of ascorbate per minute, at $25^{\circ} \mathrm{C}$. Glutathione reductase (GR) activity was determined according to Connell and Mullet (1986), following the oxidation of NADPH [the cofactor in the GR-catalysed reduction of oxidized glutathione (GSSG)] by the decrease in absorbance at $340 \mathrm{~nm}$. One GR unit was defined as the amount of enzyme that will oxidise $1 \mathrm{mmol}$ of $\mathrm{NADPH}$ per minute at $25^{\circ} \mathrm{C}$. Minor modifications to the original enzymatic assays are described in Gil et al. (2014).

\subsection{Data analyses}

Individual data of each plant ( $\mathrm{n}=5$ for each combination of variety and treatment) for all the traits measured were subjected to a two factorial (variety and drought) analysis of variance (ANOVA) including the variety $\times$ treatment interaction effect. Both variety and drought effects were treated as fixed factors. The total sums of squares were partitioned in the sums of squares for variety, treatment, variety $\times$ treatment, and residual effects. Significance of each effect was obtained from the Fvalue in the ANOVA. Significance of differences among combinations of variety and treatment were evaluated using the Student-Newman-Keuls multiple range test at $\mathrm{P}<0.05$. Pairwise phenotypic linear (Pearson) correlations among traits for individual plant data were calculated. In addition, environmental correlations (i.e., those in which the effects of variety, treatment, and the variety $\times$ treatment interaction have been removed) were calculated from the residual effects (Jackson, 1994). The signification of the calculated phenotypic and environmental correlations was evaluated with the Bonferroni test, which provides a strong control of the familywise error rate resulting from multiple pairwise correlations (Hochberg, 1988), at a significance level of $\mathrm{P}<0.05$. A principal components analysis (PCA) was performed using standardised data for the traits evaluated.

\section{Results}

\subsection{Substrate moisture analysis}

At the start of the experiment, the substrate moisture of the control and the water stress treatment were similar, with non-significant differences and values above $70 \%$. In the control treatment, the moisture content dropped quickly during the two days that 
elapsed between waterings, with values ranging between $38 \%$ and $50 \%$, indicating a high rate of water extraction by the plants. However, after watering the substrate moisture recovered, reaching values similar to those of the initial moisture content. For the water deficit treatment, the drop in substrate moisture content was similar to that of the control for the first two days. After that, a gradual reduction with time in the decreases of moisture content was observed, which obviously increased the difficulty of the plants to absorb water. In this way, the moisture content in the substrate of the drought treatment at the end of the experiment was only of $4.1 \%$ (Figure 1 ).

\subsection{Analysis of variance}

Significant differences $(\mathrm{P}<0.05)$ were detected in the ANOVA among varieties for 12 out of the 18 traits (Table 1). Traits for which no differences were observed were stem length increase, stem fresh weight (stem FW), stem water content (stem WC), malondialdehyde content, and catalase activity. For the comparison between the control and the water stress treatments, highly significant differences $(\mathrm{P}<0.001)$ were found for all traits, except for the activity of the enzymes superoxide dismutase, ascorbate peroxidase and glutathione reductase for which no significant differences were observed (Table 1). Eleven interactions between variety and treatment were significant and involved the three traits related to fresh weight (root FW, stem FW, and leaf FW), the root and stem WC, total carotenoids, proline, malondialdehyde and antioxidants contents, and the glutathione reductase activity. The percentage of sums of squares of variety ranged between $0.0 \%$ for stem $\mathrm{FW}$ and $75.4 \%$ for superoxide dismutase activity (Table 1). However, its values were very low (below 2\%) for all growth parameters (except root FW), tissue water content, proline and malondialdehyde, and low (below $10 \%$ ) for root FW and catalase activity. For the three photosynthetic pigments, and total phenolics the contribution of variety to the total sums of squares was moderate (between 14.6\% and 33.0\%), while for total flavonoids, superoxide dismutase, ascorbate peroxidase, and glutathione reductase, the variety effect was the greatest contributor to the total sums of squares, and for the three latter traits it had values above 50\% (Table 1). The water stress treatment effect was by far the greatest contributor to the total sums of squares for the rest (14) of traits, and in these cases, the value was always above $50 \%$ and reached over $75 \%$ and $95 \%$ for 12 and 7 of them, respectively. Traits for which the contribution of the water stress treatment to sums of squares was particularly high (over 75\%) included all growth and tissue water content traits, as well as chlorophylls content, 
proline content, and catalase activity (Table 1). The interaction variety $\times$ treatment had a low to moderate contribution to the total sums of squares for most traits, and only for five traits (carotenoids, malondialdehyde content, and superoxide dismutase, ascorbate peroxidase, and glutathione reductase activities) had values above $10 \%$, reaching a maximum of $23.1 \%$ for ascorbate peroxidase. The residual effect was very low for growth traits, tissues water content, photosynthetic pigments, osmolytes and antioxidants, with contributions to the total sums of squares always below 2.2\% (Table 1). For the four enzymatic activities, the contribution of the residuals to the total sums of squares was somewhat higher (between $2.8 \%$ for glutathione reductase and $10.5 \%$ for ascorbate peroxidase). In any case, the residual effect was never the first or even second contributor to the sums of squares of the four effects studied.

\subsection{Growth and tissue water content parameters}

Lack of watering for 11 days induced severe water deficit stress symptoms in the four varieties tested. Stem length elongation (Figure 2) was calculated as the difference between the length of stem at the end and at the beginning of the treatments, and a notable difference between plants from control and WS treatments was noticed, despite the brief period of time the treatments were applied. No differences were observed among varieties for the increase in length within each of the treatments. In this way, in the control plants stem length elongation varied between 7.0 and $9.4 \mathrm{~cm}$, whereas in the water stress treatment a variation between 1.0 and $3.3 \mathrm{~cm}$ was measured.

The water stress treatment had a strong effect on the fresh weight of roots, stems and leaves, with a considerable stress-induced reduction in FW in all varieties for the three traits, although it was lower for the stem FW than for the leaf FW or root FW (Figure 3). Significant differences among varieties were also found in the control plants for growth parameters. In this way, variety MEL4 had a higher root weight than the other three varieties, whereas MEL3 and MEL6 showed higher stem and leaf fresh weights. However, no differences in FW were observed among varieties subjected to water stress for any of the three FW traits measured (Figure 3). This different pattern for the FW traits in the control and stress treatments reveals that some differences existed among varieties for the percentage of reduction of FW in stressed plants as compared to the corresponding controls. For example, for root FW the reduction was of $84.6 \%$ for variety MEL4, but only 69.7\% for MEL5 (Figure 3). 
The period of water deficit applied (11 days) was long enough to induce a significant dehydration in all genotypes, in particular for roots and stems, where WC percentage was reduced to almost half in the four cultivars (Figure 3). For the stem, the reduction in WC percentage was smaller, being of only 23.7\% for MEL4. The only significant differences among varieties for the three traits in the control treatment were observed for root water content between MEL4 and MEL5, with the former showing a significantly higher value (88.2\%) than the latter (80.5\%). For the stress treatment, variety MEL6 had a higher root WC (45.2\%) than MEL5 (38.9\%), variety MEL4 had a higher stem WC (59.1\%) than the other three ( $<50 \%)$, while varieties MEL4 and MEL6 had higher leaf WC (>50\%) than MEL3 and MEL5 (<45\%) (Figure 3).

Although there were some variations among the responses of varieties depending the growth or water content parameter analysed, none of them, nor their combination, allowed a clear ranking of cultivars in terms of tolerance, with water stress affecting in a similar manner the four selected cultivars.

\subsection{Biochemical analyses}

Water deficit stress induced a significant reduction in photosynthetic pigments levels (chlorophyll a, chlorophyll b and carotenoids), with the exception of the cultivar MEL3, and also carotenoids in MEL4 (Figure 4). The strongest reduction of all pigments was noticed in MEL5 (6-fold in chlorophylls a and b, and twofold in carotenoids). Some differences among varieties were observed in the pigments contents of control plants, with MEL6 having significantly higher contents in chlorophyll a and carotenoids than the other three varieties. Also, some varietal differences were observed in stressed plants: MEL5 had significantly lower contents of the three photosynthetic pigments than MEL3 and MEL6, whereas MEL4 also had chlorophyll a levels significantly lower than those of MEL3 and MEL6 (Figure 4).

Proline concentration increased dramatically as a consequence of water stress. Leaf proline levels were above $200 \mu \mathrm{mol} \cdot \mathrm{g}^{-1}$ in the stressed plants, while they were always below $15 \mu \mathrm{mol} \cdot \mathrm{g}^{-1}$ in the controls (Figure 5). No significant differences among varieties were observed in the controls, whereas in the stress treatment varieties MEL3 and MEL4 showed significantly higher proline concentrations (322.6 and $310.6 \mu \mathrm{mol} \cdot \mathrm{g}$ ${ }^{1}$, respectively) than those of MEL5 and MEL 6 (225.2 and $218.8 \mu \mathrm{mol} \cdot \mathrm{g}^{-1}$, respectively) (Figure 5). 
Malondialdehyde also increased significantly as a consequence of water stress in MEL3 and MEL4, but not in MEL5 and MEL6. No significant differences among varieties were found in the malondialdehyde contents of control, non-stressed plants; however, under water stress conditions, values in MEL3 and MEL4 were significantly higher than those of MEL5, while the malondialdehyde concentrations measured in MEL4 plants were also significantly higher than those of MEL6 (Figure 5).

A similar pattern of variation was also observed for total phenolics and total flavonoid contents (Figure 5), which significantly increased under stress in MEL3 and MEL4, but not in MEL5 and MEL6. However, in these cases some differences existed among varieties in the control treatment, with significantly higher values of total phenolics of MEL4 compared to the rest of varieties, and also a significantly higher content in total flavonoids in MEL3 and MEL4 compared to MEL5. Also, under the drought stress treatment, values of total phenolics and total flavonoids of MEL3 and MEL4 were significantly higher than those of MEL5 and MEL6 (Figure 5).

Regarding enzyme activities, significant differences between the control and the water stress treatments for each cultivar, or among cultivars for stressed or non-stressed plants, were observed only in a few specific cases (Figure 6). Superoxide dismutase (SOD) activities did not change significantly in response to water stress, in any of the four selected eggplant varieties; however, higher levels were measured in MEL5 than in MEL3 and MEL6 in the controls, and the specific activity of this enzyme was also higher in MEL4 than in MEL6 under water stress conditions (Figure 6a). On the contrary, mean catalase (CAT) activities increased in all four varieties when the plants were subjected to water deficit, although the differences with the corresponding controls were only significant for MEL4 and MEL6; in this case, no significant differences were observed among different varieties, neither in the control treatment nor under stress conditions (Figure 6). Ascorbate peroxidase (APX) activities varied widely in the different plant samples, but the statistical analysis of the data revealed significant differences among varieties only when comparing water-stressed plants of MEL3 and MEL4, but not in the control treatments; moreover, water stress did not induce significant changes of APX activity in any of the varieties (Figure 6). Finally, the glutathione reductase (GR) specific activity of MEL3 was significantly higher than that of MEL6 under control conditions, and also higher than in stressed MEL3 plants; no other significant differences were detected when comparing all samples with each other (Figure 6). 


\subsection{Correlation analysis}

A total of 59 phenotypic correlations among individual plant data were significant according to the Bonferroni test at a significance level of $\mathrm{P}<0.05$ (Table 2). A group of traits formed by growth, tissue water content, and photosynthetic pigments generally presented significant positive phenotypic correlations among them, with a few exceptions, such as stem length increase with the three photosynthetic pigments, carotenoids content with root FW, stem FW, and leaf WC (Table 2). Also, this group of traits generally displayed significant negative phenotypic correlations with proline and malondialdehyde contents (which in turn were significantly positively correlated at the phenotypic level), with the exception of proline with carotenoids content and malondialdehyde with the three photosynthetic pigments. In particular, very high negative values, always below -0.76 , have been found for the correlations among proline and all growth and tissue water content parameters (Table 2). For malondialdehyde significant negative values, although not as high as those of proline, have also been found with all growth and tissue water content parameters. Significant positive phenotypic correlations were also detected for total phenolics content with proline, malondialdehyde, and total flavonoids (Table 2). However, no significant correlations with any other traits were detected for the activity of any of the four enzymes (Table 2).

Only eight significant environmental correlations were detected according to the Bonferroni test at $\mathrm{P}<0.05$, including those of leaf WC with root WC, stem WC and chlorophyll a. Also, the three pigments displayed a significant positive environmental correlation with each other (Table 2). Finally, total phenolics and total flavonoids also showed a significant positive environmental correlation. These eight traits for which environmental correlations were significant (positive) were also significant (and positive) in the case phenotypic correlations (Table 2).

\subsection{Principal components}

The first and second components of the PCA analysis accounted, respectively, for $53.72 \%$ and $11.57 \%$ of the total variation among individual plants (Figure 7). The loading plot of the PCA shows that the first principal component was positively correlated with all growth and tissue water content traits, as well as with photosynthetic pigments, and negatively with proline, malondialdehyde and the antioxidant compounds 
(particularly with proline and malondialdehyde contents) as well as with CAT activity. The second component was positively correlated with the photosynthetic pigments, proline, malondialdehyde and antioxidants (in particular with total phenolics and total flavonoids), and with APX and CAT activities (Figure 7).

The projection of the five individual plants of each combination of variety and treatment in the PCA score plot shows a clear separation along the first component between the plants from the control and water stress treatments, which have positive and negative values, respectively, for the first component (Figure 7). The second component separates the individuals according to variety, although this separation is clearer for the stressed plants. In this way, while in the water stress treatment the four varieties cluster in different areas of the graph, with a limited overlap between varieties MEL3 and MEL4, in the control treatment the areas of distribution of the individuals in the PCA score plot are less dispersed and the areas of distribution of each variety are overlapped, with the exception of varieties MEL5 and MEL6, individuals of the different varieties display a greater degree of admixture. Interestingly, the distribution of individuals of each variety in the control and water stress treatments have some similitudes (Figure 7). For example, MEL5 always has negative values for the second component and is the variety with lowest average values for this second component. Similarly, variety MEL6 has the highest average value for the first component for both treatments, and varieties MEL3 and MEL4 are those having a higher degree of overlap under both conditions (Figure 7).

The PCA loading plot (Figure 6) is in agreement with the phenotypic correlation values obtained (Table 2). In this way, all growth and tissue moisture traits cluster together with high values for the correlation with the first component and low absolute values for the correlation with the second component. A similar situation occurs for the three photosynthetic pigments, which cluster together with high values for the correlations with both the first and second components (Figure 6). Total phenolics and total flavonoids also cluster in the same area of the loading plot, with high values for the correlation with the second principal component and moderately negative with the first principal component.

\section{Discussion}


Although eggplant is considered as tolerant to mild water stress (Sarker et al., 2004; Díaz-Pérez and Eaton, 2015), and even among the most resilient crops to drought by some authors (Behboudian, 1977), the results obtained indicated that the complete absence of irrigation strongly affects the four cultivars of eggplants selected for the present study. Similar results were obtained by Sarker et al. (2005) when completely withholding watering in eggplant plants. In our case, after eleven days, when wilting of plants was intense and water content of the tissues revealed extreme dehydration (Rabara et al., 2015), the treatments were stopped. This brief period of lack of irrigation had a strong effect on most of the traits measured, generally higher than that of the cultivar effect, indicating that the drought stress applied was severe. In this respect, the fact that the contribution of the residual effect to the sums of squares was generally low indicates that the influence of uncontrolled environmental influences in our experiment was small, allowing a maximization of the statistical power of the experiment (Lovell, 2013).

Similar results to those obtained by us regarding a strong effect on growth and tissue water content parameters have also been reported by Gobu et al. (2017) after exposing eggplant plants to 15 days of water stress during vegetative growth. Although in our experiment some variations of growth parameters could be detected among cultivars, establishing a clear rank of drought tolerance of the four cultivars was not possible. A similar result was obtained by Tani et al. (2018) when comparing two eggplant varieties subjected simultaneously to drought stress and Verticillium dahliae infection.

Decreases in chlorophyll content, such as those observed by us, due to drought have been reported in many crops (Kiani et al., 2008; Batra et al., 2014; Dbira et al., 2018), ornamental plants (Cicevan et al., 2016), and woody species (Schiop et al., 2017; Kebbas et al., 2018). This decrease appears to be due to a combined effect of chloroplasts alteration, inhibition of enzymes such as Rubisco and PEP carboxylase, associated with chlorophyll biosynthesis and activation of chlorophyllase, involved in chlorophyll degradation (Flexas and Medrano, 2002; Munné-Bosch and Alegre, 2004). In the present experimental conditions, chlorophylls a and b levels were lower in all water stressed plants, as it has been reported in other cultivars of eggplant (Mibei et al., 2017a, Gobu et al., 2017). Chlorophyll content variation under drought has been proposed as a suitable stress marker in different eggplant materials allowing the ranking of the analysed genotypes in combination with other morphological and physiological 
parameters (Gobu et al., 2017; Sseremba et al., 2018). Of the four cultivars analysed here, the reduction in chlorophyll a and b levels was greater in MEL5, whereas it was much smaller in MEL3 and MEL6 plants.

Besides the main function of carotenoids in plants as accessory photosynthetic pigments and precursors of plant hormones, they also protect chlorophylls from destructive photooxidation, having pronounced radical scavenging and singlet oxygen quenching abilities (Edge and Truscott, 2018; Sun et al., 2018). Carotenoid concentrations were lower in the stressed plants than in their respective controls, but these differences followed the same pattern as the chlorophylls. This finding is in agreement with a carotenoid profiling in the African eggplant S. aethiopicum by Mibei et al. (2017a), who registered a drought-induced decrease of all quantified carotenoids, with the exception of zeaxanthin, and suggested that carotenoids are very susceptible to oxidative destruction in this species.

Besides the essential role of osmolytes in maintaining water absorption and turgor in the leaves, they also protect the cell membrane, stabilise enzymes, and have a protective role against oxidative stress (Ashraf and Foolad 2007; Sanders and Arndt, 2012), and generally their accumulation does not interfere with the normal cell metabolism (Singh et al., 2015). Osmolites include a large diversity of chemical compounds: amino acids (such as proline), sugars, sugar alcohols, and quaternary ammonium compounds. In this respect, proline is one of the most typical compatible solutes in plants (Verbruggen and Hermans, 2008, Szabados and Savouré, 2010) and it has been reported to significantly increase in many plant species, including Solanum melongena, under environmental stresses such as drought (Sarker et al. 2005, Tani et al. 2018), high salinity (Hassen and Al- Zubaidi, 2018; Shishira et al., 2016), or K stress (Marques et al., 2011). In all cultivars analysed in this work, proline concentration was enhanced under stress, but the increase was more pronounced in cultivars MEL3 and MEL4, whereas the lowest increment was detected in MEL5, which was the cultivar that had the highest degradation of chlorophylls and carotenoids. The increase in proline concentrations in our study was much higher than that obtained by Tani et al. (2018) in response to drought, although the drought stress treatment used by these authors was mild (25\% of field capacity) compared to ours, in which irrigation was completely withhold. However, the proline increases observed by us and concentrations in severely stressed eggplant plants in which irrigation was completely arrested is similar to the results obtained by us. Interestingly, the cultivar MEL3, which accumulated the highest 
proline concentration in water-stressed plants, showed the smallest relative reduction of photosynthetic pigments. Therefore, our results suggest that a higher concentration of proline might be related with a better adjustment to drought in S. melongena. This suggestion is supported by the results of Sarker et al. (2004), who also highlighted the essential role of proline in osmotic adjustment in one eggplant cultivar ('Baladi'), correlating increased levels of this osmolyte with the maintenance of photosynthetic activity under their experimental drought conditions. In addition, the high negative correlations betwee proline and all the growth and tissue water content parameters suggest not only a likely association of proline with tolerance to drought in eggplant, but also indicate that it could be used as a marker for drought stress tolerance in this species.

Malondialdehyde is a reactive aldehyde generated by increased free-radical production, which induces oxidation of membrane lipids, and is used as a suitable biomarker of cellular oxidative stress (Del Rio et al., 2005). Of the four cultivars, a significant increase of malondialdehyde in water-stressed plants was detected only in two cultivars (MEL3 and MEL4), but reached levels less than double than in the controls, indicating the activation of efficient antioxidant mechanisms. Although malondialdehyde is negatively correlated with all growth and tissue water content parameters, in absolute values, the correlation values are lower than those of proline, suggesting that it does not have a prominent role in the response and/or tolerance to stress in eggplant. Phenolics, especially flavonoids, are strong antioxidants in eggplant, which is included in the category of functional food, and has been ranked in the top 10 among 120 vegetables regarding antioxidant activity (Okmen et al., 2009; Hanson et al., 2006; Peng et al., 2016). In this respect, there is a wide variation of total phenolic acid content in eggplant fruits (Prohens et al., 2013). Flavonoids isolated from S. melongena fruits showed a potent free radical scavenging activity (Nisha et al., 2009). . In the four cultivars analysed here, leaf phenolic and flavonoid levels were similar in control plants, but the differences were enhanced under stress, with a pattern of variation similar to that of malondialdehyde. According to Fini et al. (2011), antioxidant phenolics and flavonoids belong to the secondary ROS scavenging systems that are activated only when the activity of the antioxidant enzymes decline under severe stress.

Of the four enzymes evaluated, CAT was the only one showing a clear increase in its specific activity in all cultivars (except MEL5) submitted to water stress. CAT acts after SOD, decomposing the generated $\mathrm{H}_{2} \mathrm{O}_{2}$ into $\mathrm{H}_{2} \mathrm{O}$ and $\mathrm{O}_{2}$, and is induced by 
accumulation of its substrate (Anjum et al., 2016; Wang et al., 2018). For the other three antioxidant enzymes tested, in general we did not detect a significant increase in activity in response to water stress, suggesting that their involvement in drought tolerance in eggplant is limited.

Our comparison of water-stressed vs. control plants by PCA analysis revealed, as in other Solanaceae plants (Rabara et al., 2015), a clear impact of the water stress treatment on the physiological and biochemical responses of eggplant to drought, as well as high correlations among morphological growth traits, and among the three photosynthetic pigments. Similarly, since flavonoids constitute the most numerous and complex subgroup of phenolic compounds (Williams and Grayer, 2004), total flavonoids and total phenolics were highly correlated. The fact that the separation in the PCA plot among varieties is much clearer under water stress than in the controls suggests that different mechanisms of response to the water stress exist in different cultivars (Obidiegwu et al., 2015; Zandalinas et al., 2018). These differences might be exploited for breeding more drought tolerant varieties of eggplant (Rauf et al., 2016).

In conclusion, although the four cultivars used displayed genetic differences (Acquadro et al., 2017) and were morphologically very different (Kaushik et al., 2016), the growth parameters analysed did not allow a clear ranking of tolerance to drought in the four eggplant genotypes analysed, as they all responded in a similar manner. Also, in the four cultivars the concentrations of the putative biochemical stress markers measured was similar in the control plants, whereas some differences were registered in the water-stressed plants. Overall, our results of correlations with growth and tissue water content parameters indicate that proline is involved in the response, and likely tolerance, to drought stress in eggplant. MEL3 and MEL4 responded in a similar manner, and differing from MEL5 and MEL6, with MEL3 and MEL4 having smaller reduction of carotenoids (and in MEL3 also of chlorophylls a and b), higher levels of proline, malondialdehyde, phenolics and flavonoids, and activation of SOD, CAT and APX enzymatic activities. These differences in the response to drought in otherwise similarly tolerant cultivars suggest that there is variability within the crop in the mechanisms of response and tolerance to drought that might be exploited for breeding. Our results provide relevant information about the physiological and biochemical responses of eggplant to drought stress. We suggest the evaluation of larger panels of eggplant genotypes and of eggplant wild relatives growing in dry habitats in order to 
identify materials of interest for breeding, as well as tolerant and susceptible cultivars that may be used as controls in this crop.

\section{Conflicts of interest}

The authors declare that there is no conflict of interest.

\section{Acknowledgements}

Authors are grateful to the European Union's Horizon 2020 Research and Innovation Programme under grant agreement No 677379 (G2P-SOL project: Linking genetic resources, genomes and phenotypes of Solanaceous crops), to Ministerio de Economía, Industria y Competitividad and Fondo Europeo de Desarrollo Regional (grant AGL2015-64755-R from MINECO/FEDER), to Ministerio de Ciencia, Innovación y Universidades, Agencia Estatal de Investigación and Fondo Europeo de Desarrollo Regional (grant RTI-2018-094592-B-100 from MCIU/AEI/FEDER, UE), to the Generalitat Valenciana and Fondo Social Europeo (Ayuda a Grupos Emergentes; GV/2019/033), to the Vicerrectorado de Investigación, Innovación y Transferencia de la Universitat Politècnica de València (Ayuda a Primeros Proyectos de Investigación; PAID-06-18), and to the initiative "Adapting Agriculture to Climate Change: Collecting, Protecting and Preparing Crop Wild Relatives", which is supported by the Government of Norway. This latter project is managed by the Global Crop Diversity Trust with the Millennium Seed Bank of the Royal Botanic Gardens, Kew and implemented in partnership with national and international gene banks and plant breeding institutes around the world. For further information see the project website: http://www.cwrdiversity.org/. Mariola Plazas is grateful to Generalitat Valenciana and Fondo Social Europeo for a post-doctoral contract (APOSTD/2018/014). The contribution of Huu Trong Nguyen to this paper has been developed as a result of a mobility stay funded by Erasmus+ KA1 Erasmus Mundus Joint Master Degrees Programme of the European Commission under the PLANT HEALTH project.

\section{References}


Acquadro, A., Barchi, L., Gramazio, P., Portis, E., Vilanova, S., Comino, C., Plazas, M., Prohens, J., Lanteri, S. 2017. Coding SNPs analysis highlights genetic relationships and evolution pattern in eggplant complexes. PLOS ONE 12, e0180774.

Aebi, H. 1984. Catalase in vitro. Method. Enzymol. 105, 121-126.

Anjum, S.A., Ashraf, U., Tanveer, M., Khan, I., Hussain, S, Shahzad, B., Zohaib, A., Abbas, F., Saleem, M.F., Ali, I., Wang, L.C. 2017. Drought induced changes in growth, osmolyte accumulation and antioxidant metabolism of three maize hybrids. Front. Plant Sci. 8, 69.

Anjum, N.A., Sharma, P., Gill, S.S., Hasanuzzaman, M., Khan, E.A., Kachhap, K., Mohamed, A.A., Thangavel, P., Devi, G.D., Vasudhevan, P., Sofo, A., Khan, N.A., Misra, A.N., Lukatkin, A.S., Singh, H.P., Pereira, E., Tuteja, N. 2016. Catalase and ascorbate peroxidase-representative $\mathrm{H}_{2} \mathrm{O}_{2}$-detoxifying heme enzymes in plants. Environ. Sci. Pollut. Res. Int.23, 19002-19029.

Anwar, M.R., Liu, D.L., Macadam, I., Kelly, G. 2013. Adapting agriculture to climate change: a review. Theor. Appl. Climatol. 113, 225-245.

Arbona, V., Manzi, M., Zandalinas, S.I., Vives-Peris, V. Pérez-Clemente, R.M., Gómez-Cadenas, A. 2017. Physiological, metabolic, and molecular responses of plants to abiotic stress, in: Sarwat, M., Ahmad, A., Abdin, M.Z., Ibrahim, M.M. (Eds.), Stress Signaling in Plants: Genomics and Proteomics Perspective, Volume 2, Springer International Publishing Switzerland, pp. 1-35.

Ashraf, M., Foolad, M.R. 2007. Roles of glycine betaine and proline in improving plant abiotic stress resistance. Environ. Exp. Bot. 59, 206-216.

Bates, L.S., Waldren, R.P., Teare, I.D. 1973. Rapid determination of free proline for water stress studies. Plant Soil 39, 205-207.

Batra N.G., Sharma, V., Kumari, N. 2014. Drought-induced changes in chlorophyll fluorescence, photosynthetic pigments, and thylakoid membrane proteins of Vigna radiata. J. Plant Interact. 9, 712-721.

Behboudian, M.H. 1977. Responses of eggplant to drought. I. Plant water balance Sci. Hort. 7, 303-310.

Beyer, W., Fridovich, I. 1987. Assaying for superoxide dismutase activity: some large consequences of minor changes in conditions. Anal. Biochem. 161, 559-566. 
Blainski, A., Lopes, G.C., de Mello, J.C.P. 2013. Application and analysis of the Folin Ciocalteu method for the determination of the total phenolic content from Limonium brasiliense L. Molecules 18, 6852-6865.

Bradford, M.M. 1976. A rapid and sensitive method for the quantitation of microgram quantities of protein utilizing the principle of protein-dye binding. Anal. Biochem. 72, 248-254.

Choudhury, F.K., Rivero, R.M., Blumwald, E., Mittler, R. 2017. Reactive oxygen species, abiotic stress and stress combination. Plant J. 90, 856-867.

Cicevan, R., Al Hassan, M., Sestras, A.F., Prohens, J., Vicente, O., Sestras, R.E., Boscaiu, M. 2016. Screening for drought tolerance in cultivars of the ornamental genus Tagetes (Asteraceae). PeerJ 4, e2133.

Connell, J.P., Mullet, J.E. 1986. Pea chloroplast glutathione reductase: purification and characterization. Plant Physiol. 82, 351-356.

Dbira, S., Al Hassan, M., Gramazio, P., Ferchichi, A., Vicente, O., Prohens, J., Boscaiu, M. 2018. Variable levels of tolerance to water stress (drought) and associated biochemical markers in Tunisian barley landraces. Molecules 23, 613.

Das, K., Roychoudhury, A. 2014. Reactive oxygen species (ROS) and response of antioxidants as ROS-scavengers during environmental stress in plants. Front. Environ. Sci. 2, 53.

Del Rio, D., Stewart, A.J., Pellegrini, N. 2005. A review of recent studies on malondialdehyde as toxic molecule and biological marker of oxidative stress. Nutr. Metab. Cardiovasc. Dis. 15, 316-328.

Díaz-Pérez, J.C., Eaton, T.E. 2015. Eggplant (Solanum melongena L.) plant growth and fruit yield as affected by drip irrigation rate. HortScience 50, 1709-1714.

Edge, R., Truscott, T.G. 2018. Singlet oxygen and free radical reactions of retinoids and carotenoids - A review. Antioxidants 7, 5.

FAO. 2019. Food and Agriculture Data. Available online at: http://www.fao.org/faostat/en/\#home (Accessed 10 February, 2019).

Fini, A., Brunetti, C., Di Ferdinando, M., Ferrini, F., Tattini, M. 2011. Stress-induced flavonoid biosynthesis and the antioxidant machinery of plants. Plant Signal. Behav. 6, 709-711.

Fita, A., Rodríguez-Burruezo, A., Boscaiu, M., Prohens, J., Vicente, O. 2015. Breeding and domesticating crops adapted to drought and salinity: A new paradigm for increasing food production. Front. Plant Sci. 6:978. 
Flexas, J., Medrano, H. 2002. Drought inhibition of photosynthesis in C3 plants: Stomatal and non-stomatal limitations revised. Ann. Bot. 89, 183-189. Fowler, C., Moore, G., Hawtin, G.C. 2003. The International Treaty on Plant Genetic Resources for Food and Agriculture: A primer for the Future Harvest Centres of the CGIAR. International Plant Genetic Resources Institute, Rome, Italy.

Gil, R., Bautista, I., Boscaiu, M., Lidón, A., Wankhade, S., Sánchez, H., Llinares, J.V., Vicente, O. 2014. Responses of five Mediterranean halophytes to seasonal changes in environmental conditions. AoB Plants 6, plu049.

Gill, S., Tuteja, N. 2010. Reactive oxygen species and antioxidant machinery in abiotic stress tolerance in crop plants. Plant Physiol. Biochem. 48, 909-930.

Gobu, R.B.N., Babu, B.N.H., Chandra, Shankar K.M., Prakash, O. 2017. Effect of moisture stress on key physiological traits in brinjal (Solanum melongena L.) cultivars. Vegetos 30, 403-408.

Hanson, P.M., Yang, R.Y., Tsou, S.C.S., Ledesma, D., Engle, L., Lee, T.C. 2006. Diversity in eggplant (Solanum melongena) for superoxide scavenging activity, total phenolics, and ascorbic acid. J. Food Compos. Anal. 19, 594-600.

Hassen, A., Al-Zubaidi, A. 2018. Effects of salinity stress on growth and yield of two varieties of eggplant under greenhouse conditions. Res. Crops 19, 436-440.

Helyes, L., Nagy, Z., Daood, H., Pék, Z., Lugasi A. 2015. The simultaneous effect of heat stress and water supply on total polyphenol content in eggplant. Appl. Ecol. Environ. Res. 13:583-595.

Hochberg, Y. 1988. A sharper Bonferroni procedure for multiple tests of significance. Biometrika 75, 800-803.

Hodges, D.M., DeLong, J.M., Forney, C.F., Prange, R.K. 1999. Improving the thiobarbituric acid-reactive-substances assay for estimating lipid peroxidation in plant tissues containing anthocyanin and other interfering compounds. Planta 207, 604-611.

IPCC. 2014. Intergovernmental panel on climate change. In: Proceedings of the 5th Assessment Report, WGII, Climate Change 2014: Impacts, Adaptation, and Vulnerability (Cambridge: Cambridge University Press). Available at: http:// www.ipcc.ch/report/ar5/wg2/ [accessed on February 25, 2019].

Jackson, P. 1994. Genetic relationships between attributes in sugarcane clones closely related to Saccharum spontaneum. Euphytica 79, 101-108. 
Karam, F., Saliba R., Skaf, S., Breidy, J., Rouphael, Y., Balendonck, J. 2011. Yield and water use of eggplants (Solanum melongena L.) under full and deficit irrigation regimes. Aust. J. Agric. Res. 53:1367-1373.

Karuppanapandian,T., Moon, J.C., Kim, C., Manoharan, K., Kim, W. 2011. Reactive oxygen species in plants: their generation, signal transduction, and scavenging mechanisms. Aust. J. Crop Sci. 5, 709-725.

Kaur, G., Asthir, B. 2015. Proline: a key player in plant abiotic stress tolerance. Biol. Plant. 59, 609-619.

Kaushik, P., Prohens, J., Vilanova, S., Gramazio, P., Plazas, M. 2016. Phenotyping of eggplant wild relatives and interspecific hybrids with conventional and phenomics descriptors provides insight for their potential utilization in breeding. Front. Plant Sci. 7, 677.

Kebbas, S., Benseddik, T., Makhloufi, H., Aid, F. 2018. Physiological and biochemical behaviour of Gleditsia triacanthos L. young seedlings under drought stress conditions. Not. Bot. Horti Agrobo. 46, 585-592.

Kiani, S.P., Maury, P., Sarrafi, A., Grieu, P. 2008. QTL analysis of chlorophyll fluorescence parameters in sunflower (Helianthus annuus L.) under wellwatered and water-stressed conditions. Plant Sci. 175, 565-573.

Kirnak, H., Tas, I., Kaya, C., Higgs, D. 2002. Effect of deficit irrigation on growth, yield and fruit quality of eggplant under semi-arid conditions. Aust. J. Agric. Res. 53,1367-1373.

Lichtenthaler, H. K., Wellburn, A.R. 1983. Determinations of total carotenoids and chlorophylls a and b of leaf extracts in different solvents. Biochem. Soc. Trans. 11, 591-592.

Lovell, D.P. 2013. Biological importance and statistical significance. J Agric. Food Chem. 61, 8340-8348.

Lovelli, S., Perniola, M., Ferrara, A., Di Tommaso, T. 2007. Yield response factor to water (Ky) and water use efficiency of Carthamus tinctorius L. and Solanum melongena L. Agric. Water Manag. 92, 73-80.

Marques, D.J., Broetto, F., da Silva, E.C., Nunes de Freitas, J.M., da Silva Lobato, A.K., Ruffeil Alves, G.A. 2011. Changes in leaf proline and fruit production induced by potassium stress in eggplant. J. Food Agric. Environ. 9, 191-194. 
Mibei E.K., Ambuko, J., Giovannoni, J.J., Onyango, A.N., Owino, W.O. 2017a. Carotenoid profiling of the leaves of selected African eggplant accessions subjected to drought stress. Food Sci. Nutr. 5, 113-122.

Mibei, E.K., Owino, W.O., Ambuko, J., Giovannoni, J.J., Onyango, A.N. 2017b. Metabolic analyses to evaluate the effect of drought stress on selected African eggplant accessions. J. Sci. Food Agric. 98, 205-216.

Munné Bosch, S., Allegre, I. 2004. Die and let live: leaf senescence contributes to plant survival under drought stress. Funct. Plant Biol. 31, 203-216.

Nakano, Y., Asada, K. 1981. Hydrogen peroxide is scavenged by ascorbate-specific peroxidase in spinach chloroplasts. Plant Cell Physiol. 22, 867-880.

Nakashima, K., Suenaga, K. 2017. Toward the genetic improvement of drought tolerance in crops. Jpn. Agr. Res. Qtly. 51, 1-10.

Nisha, P., Abdul Nazar, P., Jayamurthy P. 2009. A comparative study on antioxidant activities of different varieties of Solanum melongena. Food Chem. Toxicol. 47, 2640-2644.

Obidiegwu, J.E., Bryan, G.J., Jones, H.G., Prashar, A. 2015. Coping with drought: stress and adaptive responses in potato and perspectives for improvement. Front. Plant Sci. 6, 542.

Okmen, B., Sigva, H.O., Mutlu, S., Doganlar, S., Yemenicioglu, A., Frary, A. 2009. Total antioxidant activity and total phenolic contents in different Turkish eggplant (Solanum melongena L.) cultivars. Intl. J. Food Prop.12, 616-624.

Panche, A., Diwan, A., Chandra, S. 2016. Flavonoids: an overview. J. Nutr. Sci. 5, E47.

Peng, H., Yang, T., Whitaker, B.D., Trouth, F., Shangguan, L., Dong, W., Jurick, W.M. 2016. Characterization of spermidine hydroxycinnamoyl transferases from eggplant (Solanum melongena L.) and its wild relative Solanum richardii Dunal. Hort. Res. 3, 62.

Prohens, J., Plazas, M., Raigón, M.D., Seguí-Simarro, J.M., Stommel, J.R., Vilanova, S. 2012. Characterization of interspecific hybrids and first backcross generations from crosses between two cultivated eggplants (Solanum melongena and $S$. aethiopicum Kumba group) and implications for eggplant breeding. Euphytica 186, 517-538.

Prohens, J., Whitaker, B.D., Plazas, M., Vilanova, S., Hurtado, M., Blasco, M., Gramazio, P., Stommel, J.R. 2013. Genetic diversity in morphological characters and phenolic acids content resulting from an interspecific cross between 
eggplant, Solanum melongena, and its wild ancestor (S. incanum). Ann. Appl. Biol. 162, 242-257.

Rabara, R.C., Tripathi, P., Reese, R.N., Rushton, D.L., Alexander, D., Timko, M.P., Shen, Q.J., Rushton, P.J. 2015. Tobacco drought stress responses reveal new targets for Solanaceae crop improvement. BMC Genomics 16:484.

Ranil, R.H.G., Niran, H.M.L., Plazas, M., Fonseka, R.M., Fonseka, H.H., Vilanova, S., Andújar, I., Gramazio, P., Fita, A., Prohens, J. 2015. Improving seed germination of the eggplant rootstock Solanum torvum by testing multiple factors using an orthogonal array design. Sci. Hort. 193, 174-181.

Rauf, S., Al-Khayri, J.M., Zaharieva, M., Monneveux, P., Khalil, F. 2016. Breeding strategies to enhance drought tolerance in crops, in Al-Khayri, J.M., Jain, S., Johnson, D. (Eds.), Advances in Plant Breeding Strategies: Agronomic, Abiotic and Biotic Stresses. Springer, Cham, Switzerland, pp. 397-445.

Sanders, G.J., Arndt, S.K. 2012. Osmotic adjustment under drought conditions, in: Aroca R. (Ed.), Plant Responses to Drought Stress. Springer, Berlin, pp. 199229.

Sarker, B.C., Hra, M., Uemura, M. 2004. Comparison of response of two C3 species to leaf water relation, proline synthesis, gas exchange and water use under periodic water stress. Plant Biol. 47, 33-41.

Sarker, B.C., Hra, M., Uemura, M. 2005. Proline synthesis, physiological responses and biomass yield of eggplants during and after repetitive soil moisture stress. Sci. Hort. 103, 387-402.

Schiop, S., Al Hassan, M., Sestras, A., Boscaiu, M., Sestras, R., Vicente, O. 2017. Biochemical responses to drought, at the seedling stage, of several Romanian Carpathian populations of Norway spruce (Picea abies L. Karst). Trees 31, 1479-1490.

Shishira T., Nivedita P., D’souza Myrene, R., Singh Kavitha, G. 2016. Antioxidant marker response of Solanum melongena to salinity stress. J. Chem. Pharm. Res. 8, 533-539.

Singh, M., Kumar, J., Singh, S., Singh, V.P., Prasad, S.M. 2015. Roles of osmoprotectants in improving salinity and drought tolerance in plants: a review. Environ. Sci. Biotechnol. 14, 407.

Singh, A., Sharma, M.K., Sengar, R.S. 2017. Osmolytes: proline metabolism in plants as sensors of abiotic stress. J. Appl. \& Nat. Sci. 9, 2079 -2092. 
Sseremba, G., Tongoona, P., Eleblu, P., Danquaha, E.Y., Kizito, E.B. 2018. Heritability of drought resistance in Solanum aethiopicum Shum group and combining ability of genotypes for drought tolerance and recovery. Sci. Hort. 240, 213-220.

Sun, T., Yuan, H. Cao, H., Yazadani, M., Tadmor, Y., Li, L. 2018. Carotenoid metabolism in plants: The role of plastids. Mol. Plant 8, 58-74.

Szabados, L., Savouré, A. 2010. Proline: a multifunctional amino acid. Trends Plant Sci. 15, 89-97.

Tani, E., Kizis, D., Markellou, E., Papadakis, I., Tsamadia, D., Leventis, G., Makrogianni, D., Karapanos, I. 2018. Cultivar-dependent responses of eggplant (Solanum melongena L.) to simultaneous Verticillium dahliae infection and drought. Front. Plant Sci. 9, 1181.

Uddin, M.N., Hossain, M.A., Burrit, D.J. 2016. Salinity and drought stress: similarities and differences in oxidative responses and cellular redox regulation, in: Parvaiz A. (Ed.), Water Stress and Crop Plants: A Sustainable Approach, Volume 1, , John Wiley \& Sons, Chichester, West Sussex, pp. 86-101.

Van Oosten, M.J., Costa, A., Punzo, P., Landi, S., Ruggiero, A., Batelli, G., Grillo, S. 2016. Genetics of drought stress tolerance in crop plants, in: Hossain, M.A., Wani, S.H., Bhattachajee, S., Burritt, D.J., Tran, L.-S.P. (Eds.), Drought Stress Tolerance in Plants, Volume 2, Springer International Publishing, Switzerland pp. 39-70.

Verbruggen, N., Hermans, C. 2008. Proline accumulation in plants: a review. Amino Acids 35, 753-759.

Vicente, O., Boscaiu, M. 2018. Flavonoids: antioxidant compounds for plant defence... and for a healthy human diet. Not. Bot. Horti Agrobo.46, 14-21.

Wang, Y., Branicky, R., Noë, A., Hekimi, S. 2018. Superoxide dismutases: dual roles in controlling ROS damage and regulating ROS signalling. J. Cell Biol. 217, 1915, doi: 10.1083/jcb.201708007.

Williams, C.A., Grayer, R.J. 2004. Anthocyanins and other flavonoids. Nat. Prod. Rep. 21, 539-573.

Zandalinas, S. I., Mittler, R., Balfagón, D., Arbona, V., Gómez-Cadenas, A. 2018. Plant adaptations to the combination of drought and high temperatures. Physiol. Plant. 162, 2-12. 
Zhishen, J., Mengcheng, T., Jianming, W. 1999. The determination of flavonoid contents in mulberry and their scavenging effects on superoxide radicals. Food Chem. 64, 555-559. 
Table 1. Percentage of the total sums of squares for each trait for the effects of variety, treatment, interaction between variety and treatment, and residual.

\begin{tabular}{lcccc}
\hline \multirow{2}{*}{ Traits } & \multicolumn{3}{c}{ Sums of squares $^{\mathrm{a}}$} \\
\cline { 2 - 5 } d.f. $^{\text {Variety }}$ & Treatment & Variety x Treatment & Residual \\
Stem Length Increase & $1.5^{\mathrm{ns}}$ & \multicolumn{2}{c}{ Growth } & 32 \\
Root FW & $6.4^{* * *}$ & $87.6^{* * *}$ & $1.2^{\mathrm{ns}}$ & 0.7 \\
Stem FW & $0.0^{\mathrm{ns}}$ & $98.5^{* * *}$ & $5.5^{* * *}$ & 0.2 \\
Leaf FW & $0.7^{* *}$ & $98.5^{* * *}$ & $1.3^{* *}$ & 0.2 \\
& & & $0.7^{* *}$ & 0.1
\end{tabular}

Tissues water content

$\begin{array}{lllll}\text { Root WC } & 0.3^{*} & 99.4^{* * *} & 0.3^{*} & 0.1 \\ \text { Stem WC } & 0.5^{\mathrm{ns}} & 97.7^{* * *} & 1.6^{* *} & 0.3 \\ \text { Leaf WC } & 1.9^{* *} & 96.8^{* * *} & 1.1^{\mathrm{ns}} & 0.3\end{array}$

Chlorophyll a

Photosynthetic pigments

Chlorophyll b

$14.6^{* * *}$

$81.7^{* * *}$

$2.5^{\text {ns }}$

Carotenoids

$16.7^{* * *}$

$77.4^{* * *}$

$3.8^{\mathrm{ns}}$

$23.6^{* * *}$

$63.1^{* * *}$

$11.1^{* *}$

Proline, malondialdehyde and antioxidants

Proline

$1.2^{* *}$

$97.6^{* * *}$

$1.0^{* *}$

Malondialdehyde

$1.2^{\mathrm{ns}}$

$84.2^{* * *}$

$12.9^{* * *}$

Total phenolics

$33.0^{* * *}$

$59.8^{* * *}$

$6.3^{* *}$

1.0

Total flavonoids

$47.1^{* * *}$

$45.5^{* * *}$

$5.7^{*}$

1.8

Enzymatic activity

SOD

$75.4^{* * *}$

$3.3^{\mathrm{ns}}$

$14.6^{\mathrm{ns}}$

6.7

CAT

$9.4^{\mathrm{ns}}$

$77.6^{* * *}$

$8.4^{\mathrm{ns}}$

4.5

APX

$53.4^{* *}$

$13.0^{\mathrm{ns}}$

$23.1^{\text {ns }}$

10.5

GR

$68.1^{* * *}$

$10.0^{\mathrm{ns}}$

$19.0^{* *}$

2.8

a ns ${ }^{*},{ }^{* *}$, and ${ }^{* * *}$ indicate, respectively, non-significant, and significant at $\mathrm{P}<0.05,<0.01$, or $<0.001$.

${ }^{\mathrm{b}}$ Degrees of freedom in the ANOVA analyses. 
Table 2. Phenotypic (above diagonal) and environmental (below diagonal) correlations among the morphological, physiological and biochemical traits measured in the 40 eggplant individuals corresponding to four varieties (MEL3-MEL6) subjected to two treatments (control and water stress). Values in bold are significant according to the Bonferroni test at $\mathrm{P}<0.05$. The correlations involving the four enzyme activities (SOD, CAT, APX, GR) are not displayed as none of the correlations of any of these enzymes was significant according to the Bonferroni test.

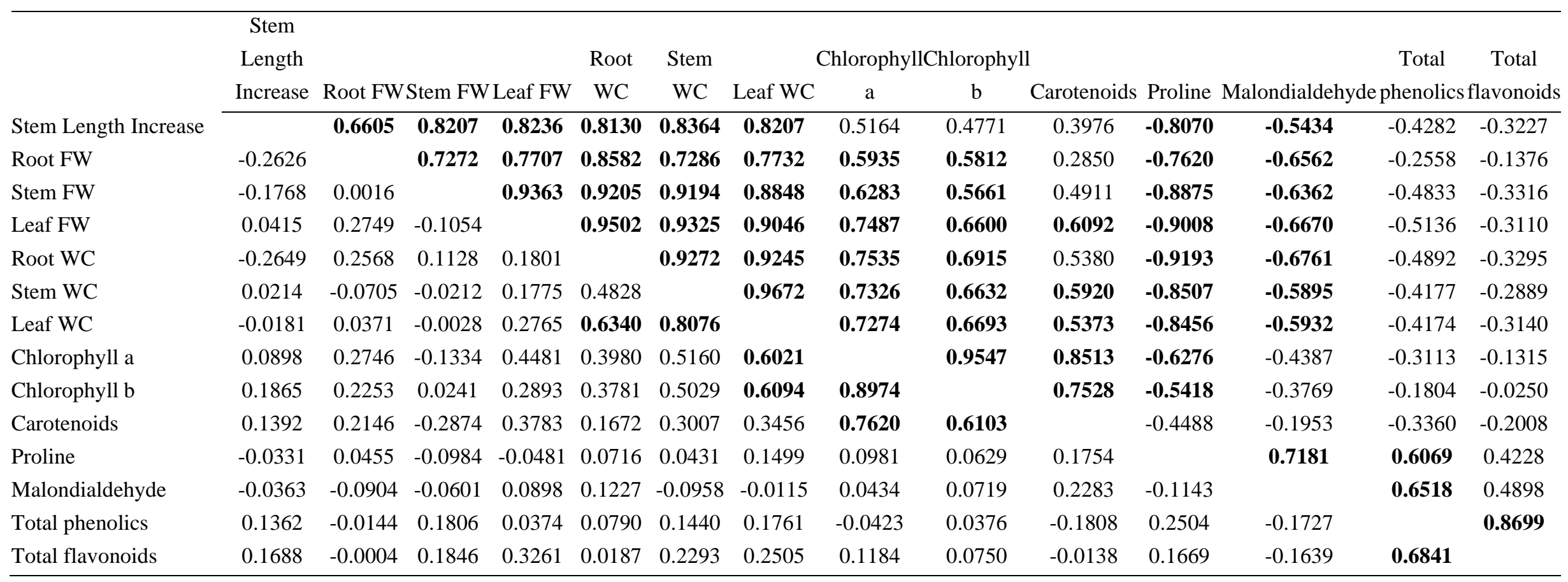




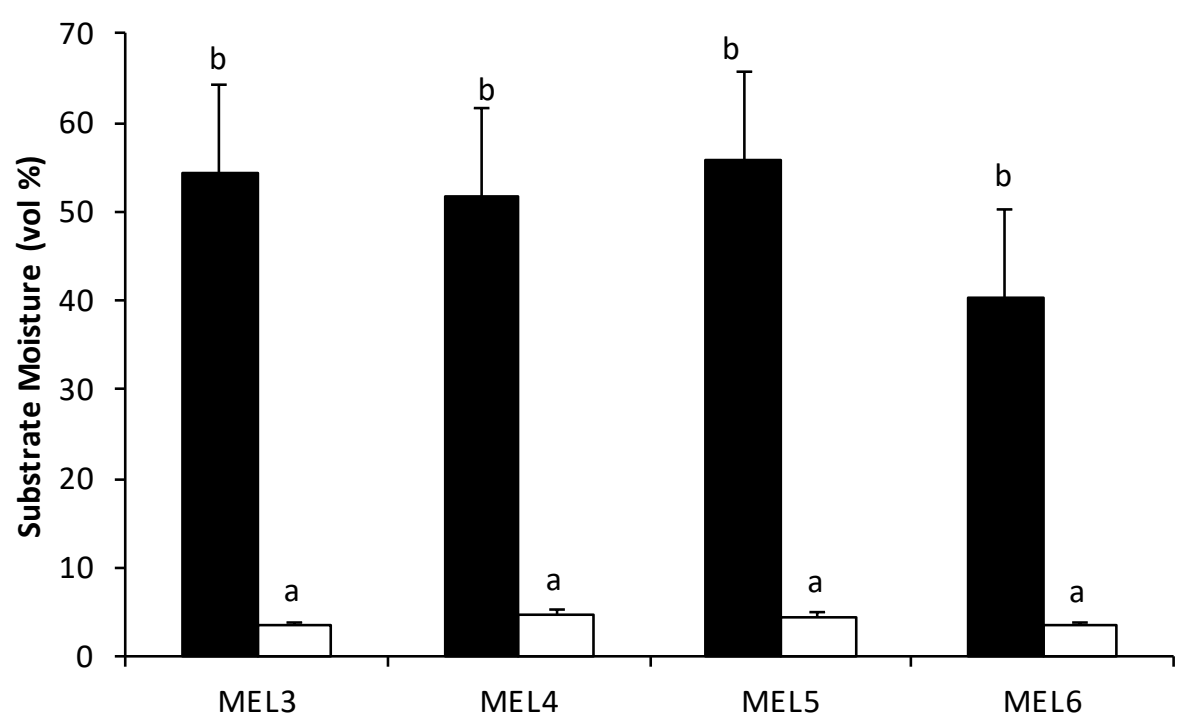

Figure 1. Pot substrate moisture (\%) for the control (black columns) and water stress (white columns) treatments in four eggplant varieties (MEL3-MEL6) after 11 days of treatment. Bars represent the SE $(n=5)$. Means for the combination of treatment and variety separated by different letters are significant $(\mathrm{P}<0.05)$ according to the StudentNewman-Keuls multiple range test. 


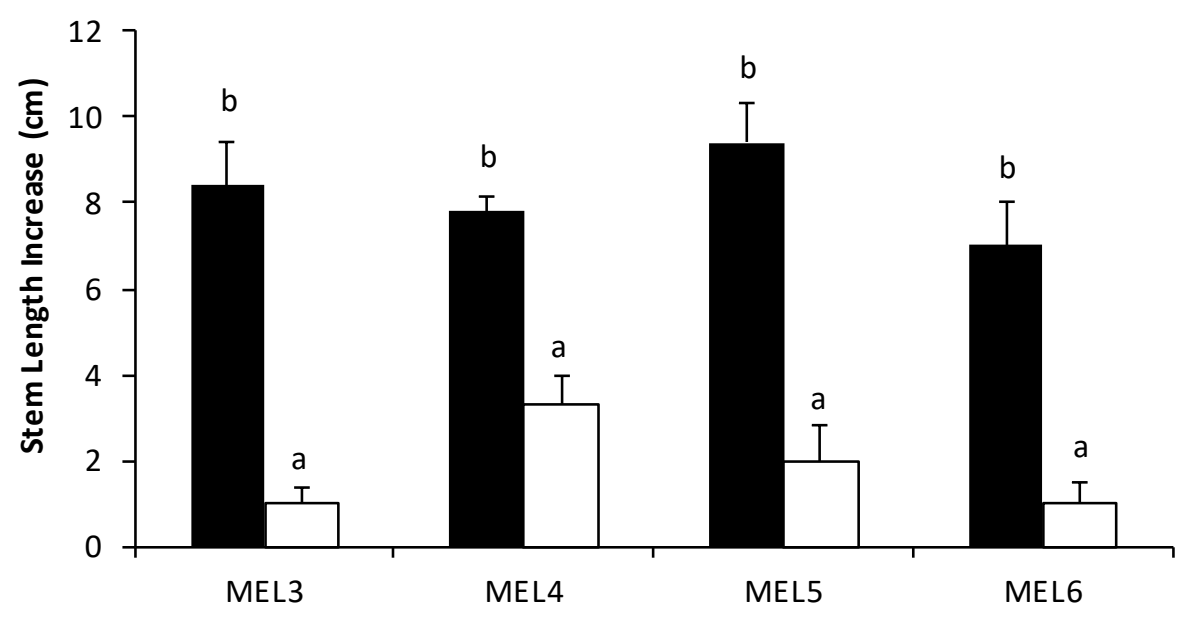

Figure 2. Stem length increase for the control (black columns) and water stress (white columns) treatments in four eggplant varieties (MEL3-MEL6) after 11 days of treatment. Bars represent the SE $(n=5)$. Means for the combination of treatment and variety separated by different letters are significant $(\mathrm{P}<0.05)$ according to the StudentNewman-Keuls multiple range test. 

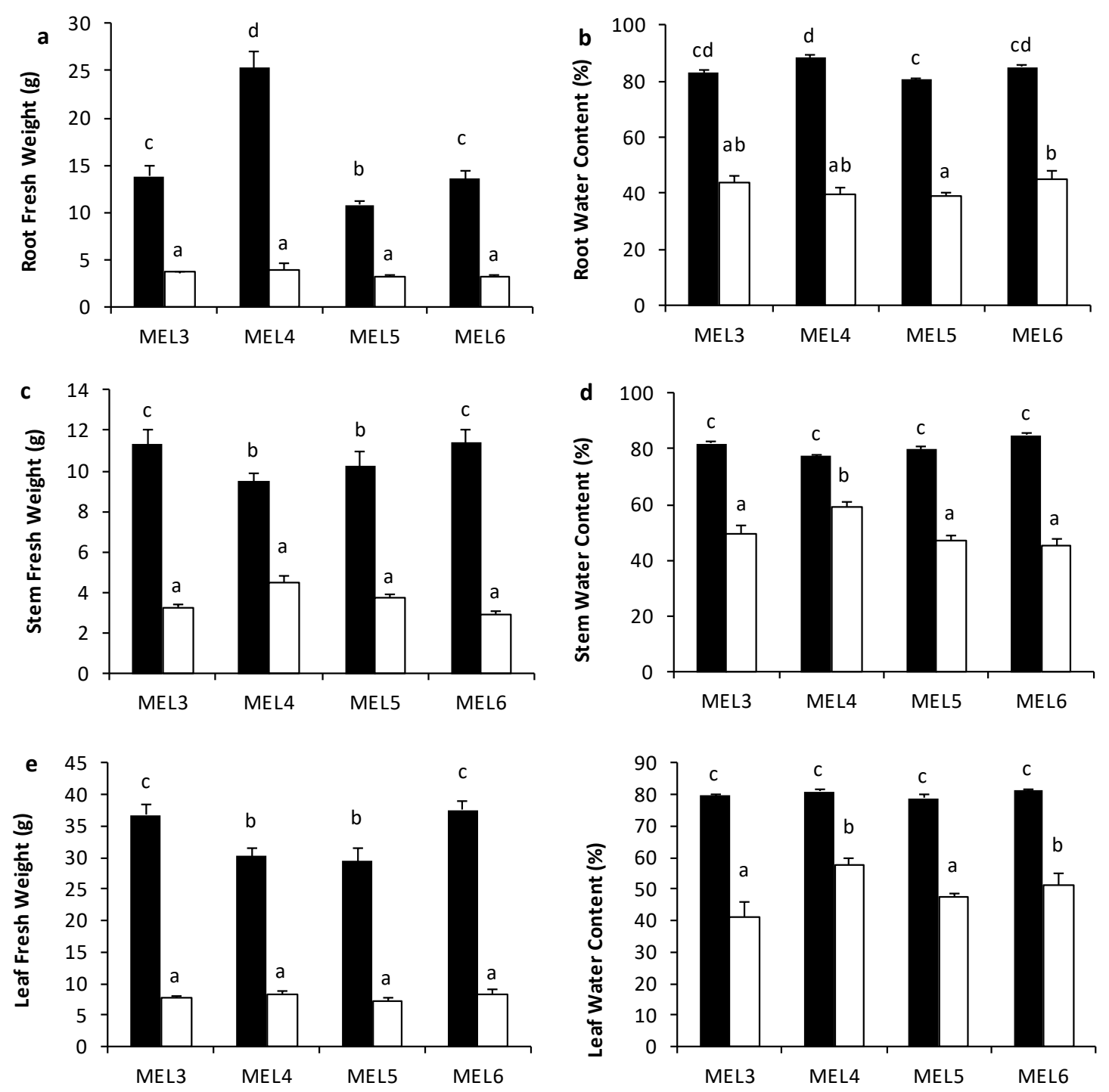

Figure 3. Fresh weight and water content of the root (a, b), stem (c, d) and leaf (e,f) for the control (black columns) and water stress (white columns) treatments in four eggplant varieties (MEL3-MEL6) after 11 days of treatment. Bars represent the SE $(n=5)$. For each trait, means for the combination of treatment and variety separated by different letters are significant $(\mathrm{P}<0.05)$ according to the Student-Newman-Keuls multiple range test. 

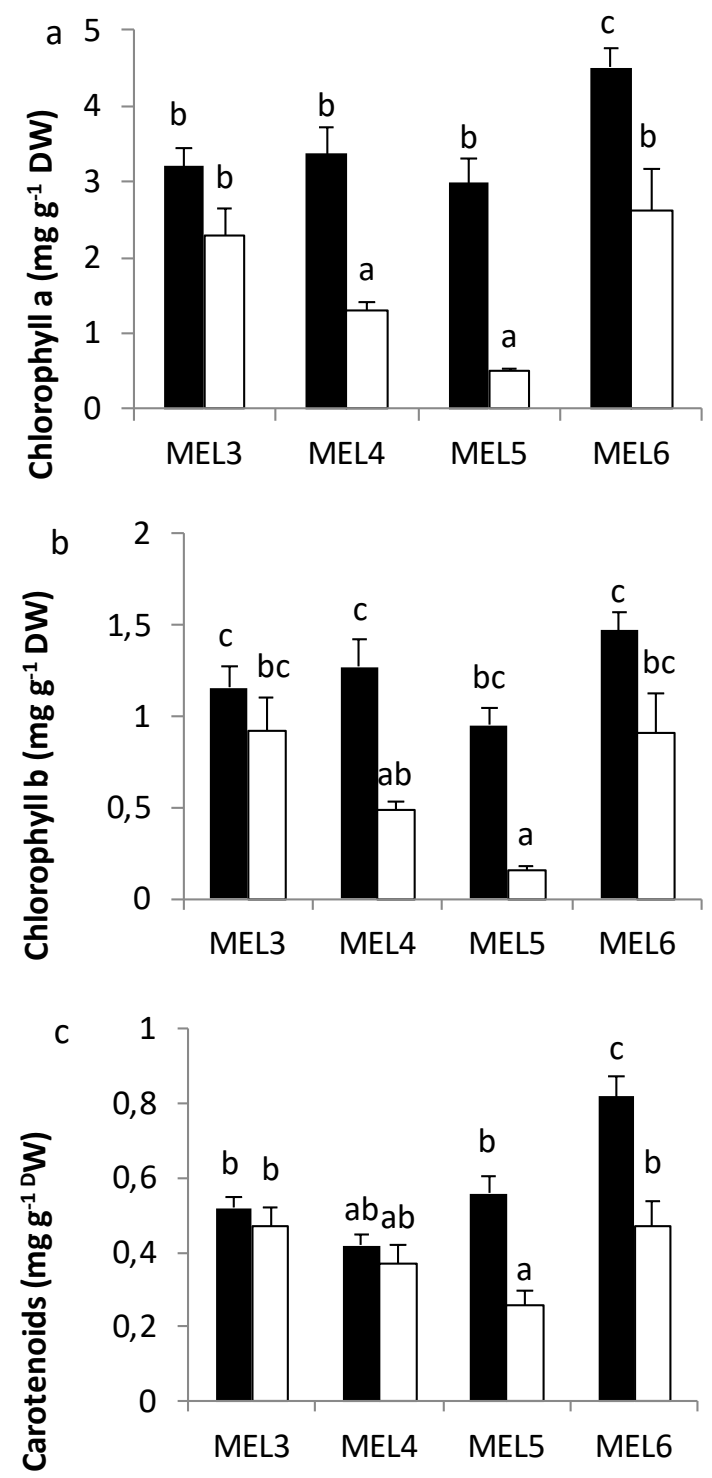

Figure 4. Chlorophylls a (a) and b (b), total carotenoids (c) for the control (black columns) and water stress (white columns) treatments in four eggplant varieties (MEL3MEL6) after 11 days of treatment. Bars represent the SE ( $n=5)$. For each trait, means for the combination of treatment and variety separated by different letters are significant $(\mathrm{P}<0.05)$ according to the Student-Newman-Keuls multiple range test. 

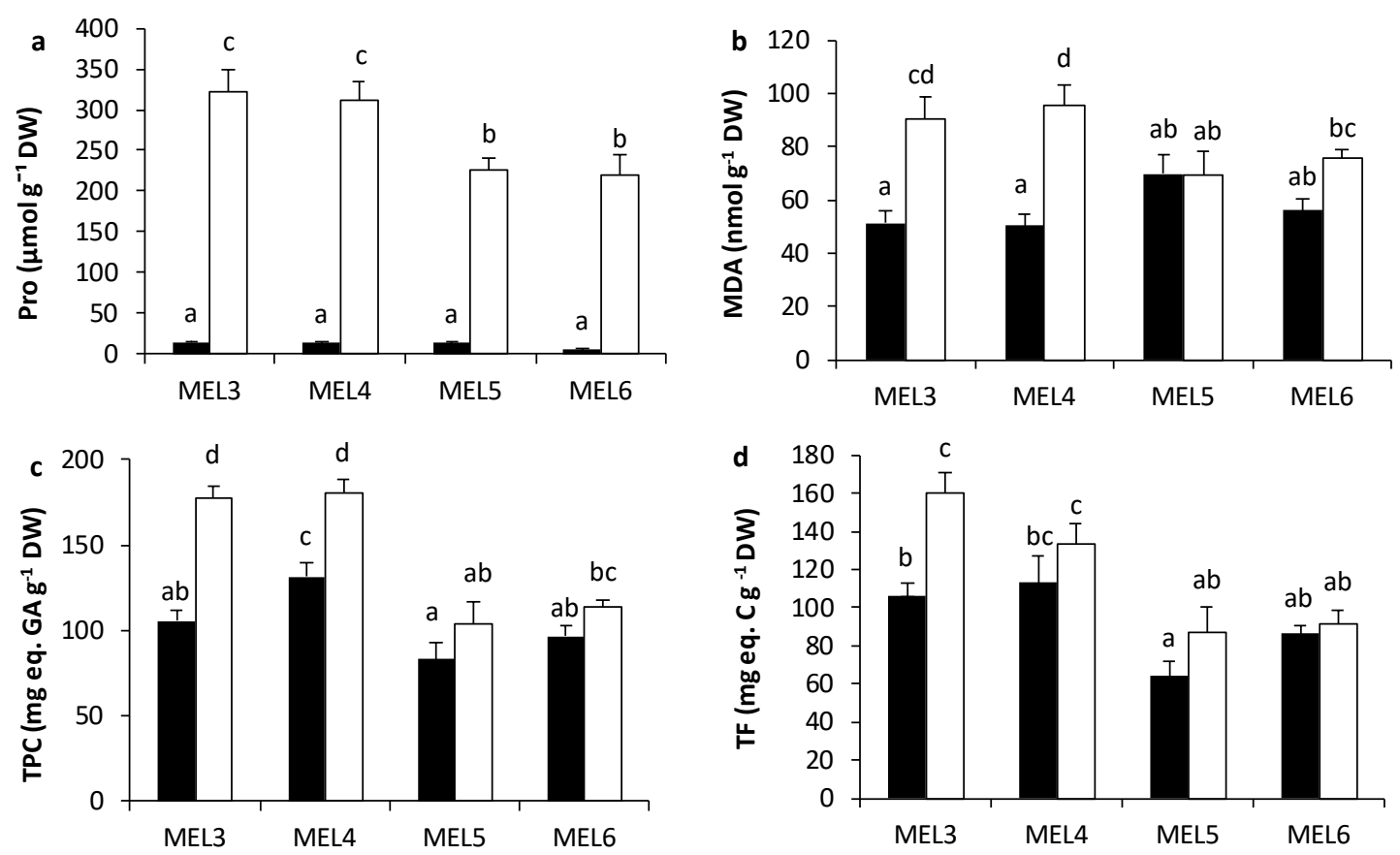

Figure 5. Proline (Pro; a), malondialdehyde (MDA; b), total phenolics (TPC; c), and total flavonoids (TF; d) contents, for the control (black columns) and water stress (white columns) treatments in four eggplant varieties (MEL3-MEL6) after 11 days of treatment. Bars represent the SE $(n=5)$. For each trait, means for the combination of treatment and variety separated by different letters are significant $(\mathrm{P}<0.05)$ according to the Student-Newman-Keuls multiple range test. 

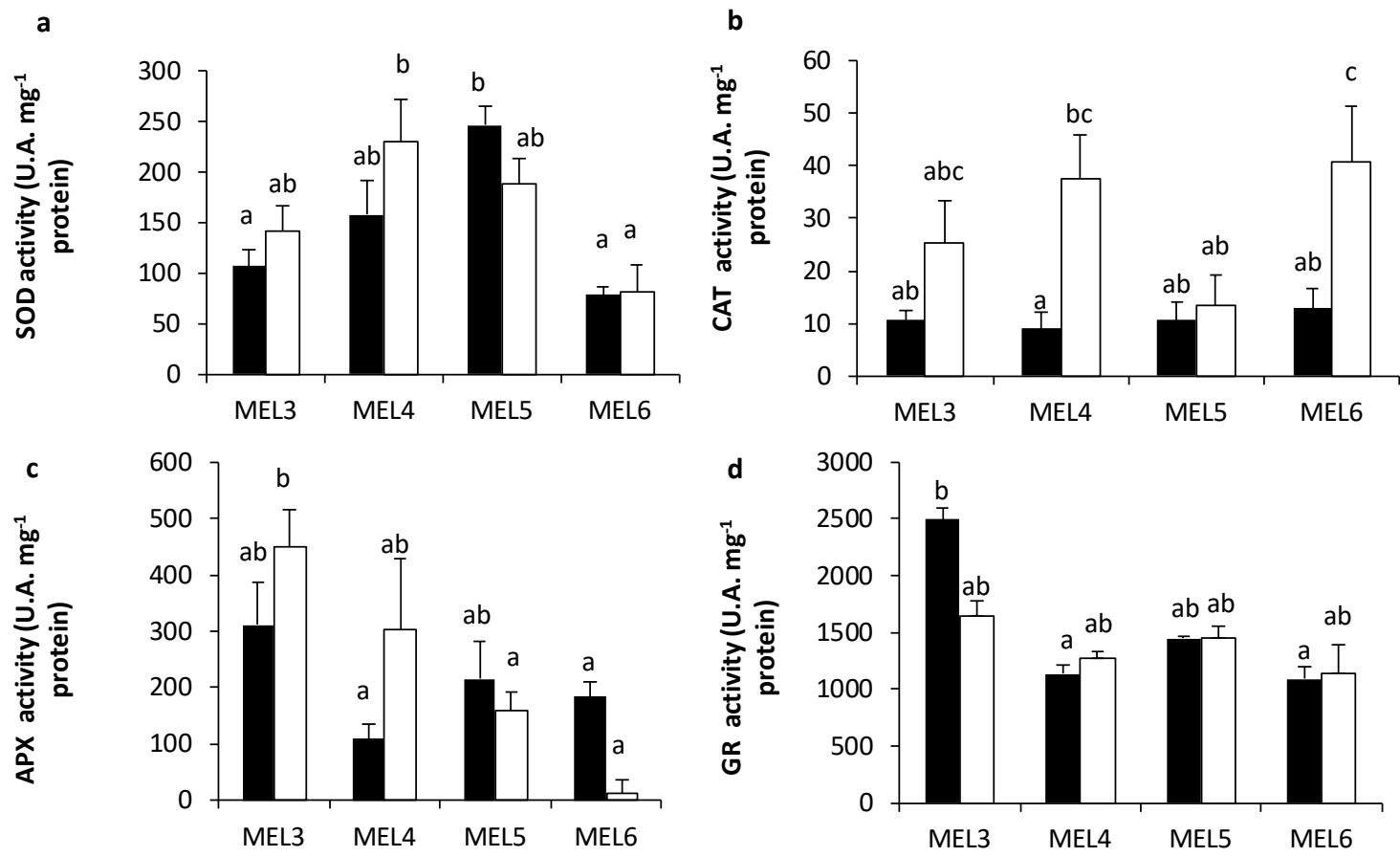

Figure 6. Superoxide dismutase (SOD; a), catalase (CAT; b), ascorbate peroxidase (APX; c), and glutathione reductase (GR; d) enzyme activities for the control (black columns) and water stress (white columns) treatments in four eggplant varieties (MEL3MEL6) after 11 days of treatment. Bars represent the SE (n=5). For each trait, means for the combination of treatment and variety separated by different letters are significant $(\mathrm{P}<0.05)$ according to the Student-Newman-Keuls multiple range test. 

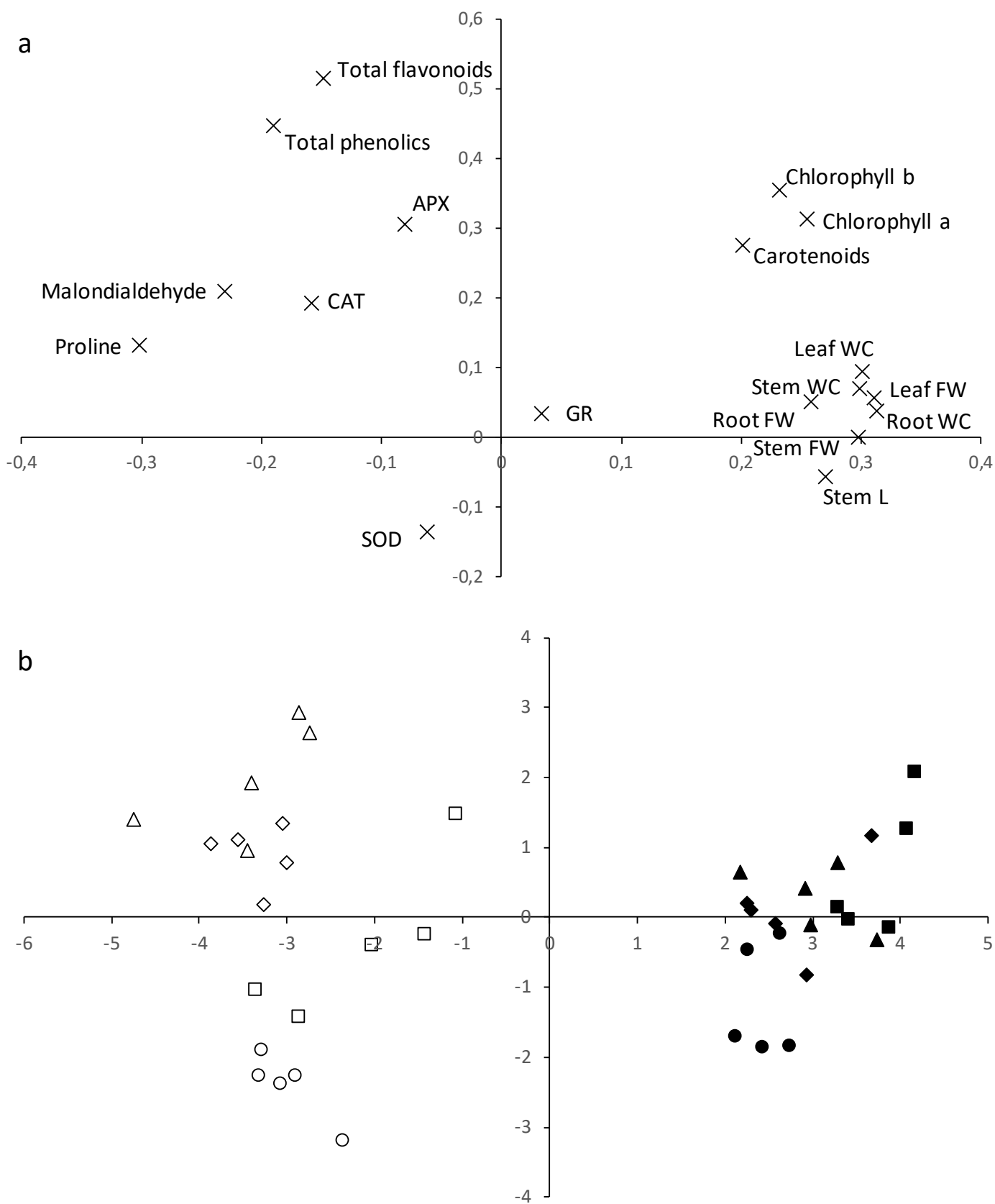

Figure 7. Diagram showing the relationships among the 18 morphological, physiological and biochemical traits (above; a) and among the 40 eggplant individuals from four varieties (MEL3-MEL6) subjected to two treatments (control vs. water stress) (below; b) based on the two first principal components of a principal components analysis (PCA). The first and second principal components account, respectively for $53.72 \%$ and $11.57 \%$ of the total variation. The four varieties are represented in the accessions plot (below; b) by different symbols: triangle for MEL3, diamond for MEL4, 
circle for MEL5, and square for MEL6. Solid and open symbols represent, respectively, the control and water stress treatments. 